\title{
Enhanced Vitellogenin Induction of Secondary Effluents by Chlorination
}

\author{
L. An, ${ }^{1,2}$ J. Hu, ${ }^{2}$ M. Yang, ${ }^{1}$ F. Jin, ${ }^{1}$ Q. Du, ${ }^{3}$ Z. $\mathrm{Ke}^{3}$ \\ ${ }^{1}$ State Key Laboratory of Environmental Aquatic Chemistry, Research Center for \\ Eco-Environmental Sciences, Chinese Academy of Sciences, Beijing, 100085, \\ People's Republic of China \\ ${ }^{2}$ College of Environmental Science, Peking University, Beijing, 100871, People's \\ Republic of China \\ ${ }^{3}$ Center of Water Quality Testing of Gaobeidian STP, 100025, People's Republic \\ of China
}

Received: 1 July 2005/Accepted: 25 May 2006

Previous work has demonstrated the presence of both male and female gonad characteristics within the same fish (Rutilus rutilus). These fish were found inhabiting freshwater near treated wastewater discharges (Jobling et al. 1998). This phenomenon has been linked with both domestic and municipal sewage effluents. It was reported that dose- and time-dependent induction of plasma vitellogenin (VTG, the precursor of yolk protein) occurred in caged fish exposed to municipal sewage effluents, and the persistent feminization of the reproductive ducts in presumed male fish has been found (Rodgers-Gray et al. 2000; 2001). These studies mainly focused on evaluating estrogenic activity in municipal sewage effluents treated with conventional processes. Although chlorination is often used in treatment processes in sewage treatment plants (STPs), the effects of chlorination on the estrogenic activity of secondary effluents are unclear.

In this study, zebrafish (Danio rerio) VTG (zf - VTG) and medaka early - life development were used to monitor the effects of estrogenic activity in chlorinated secondary effluent from Fangzhuang STP in Beijing, which was compared with that in secondary effluent. Eleven polycyclic aromatic hydrocarbons (PAHs), from the 16 PAHs suggested by the US EPA as the principal contaminants in effluents before and after chlorination, were also analyzed.

\section{MATERIALS AND METHODS}

The standards of PAHs (naphthalene, acenaphthene, phenanthrene, anthracene, fluoranthene, pyrene, benzo(a)anthracene, chrysene, benzo(a)pyrene, indeno(1,2,3-cd)pyrene, and dibenzo(a,h)anthracene were purchased from SUPELCO (USA). Hexane and dichloromethane were HPLC grade.

The secondary effluents after conventional treatment processes in Fangzhuang STP were transported to the lab every day. First, the effluent was chlorinated with $5 \mathrm{mg} / \mathrm{L} \mathrm{NaOCl}$ for two hours. Then, the surplus chlorine was removed by adding

$\overline{\text { Correspondence to }}$ : $\mathrm{J} . \mathrm{Hu}$ 
sodium thiosulfate $\left(\mathrm{Na}_{2} \mathrm{~S}_{2} \mathrm{O}_{4}\right)$, and the $\mathrm{pH}$ was adjusted to $7.8 \pm 0.2$. Tap water filtered through activated carbon was used as the control. A laboratory-constructed flow-through system was employed. Each unit of the system was composed of two chambers with a volume of 40 liters for exposure and 100 liters for cycling of the effluents. Twenty mature male zebrafish (length $=3.50 \pm 0.50 \mathrm{~cm}$; weight $=0.25 \pm$ $0.05 \mathrm{~g}$ ) were exposed to secondary effluent and chlorinated secondary effluent, of which $40 \%$ was changed every day. The fish were fed twice with commercial pellets (less than $5 \%$ of body weight/day) every day and the remaining food was removed after one hour. The temperature was controlled at $23 \pm 1{ }^{\circ} \mathrm{C}$, and dissolved oxygen content saturation was kept above $4.0 \mathrm{mg} / \mathrm{L}$. The photoperiod was automatically maintained at $14 \mathrm{hr}$ (light): $10 \mathrm{hr}$ (dark). After 2 weeks, the zebrafish were frozen in liquid nitrogen in order to analyze VTG.

The whole body was homogenized in buffer $(10 \mathrm{mM}$ Tris- $\mathrm{HCl}$ containing $0.9 \%$ $\mathrm{NaCl}, 0.05 \%$ Tween $20,1 \% \mathrm{BSA}, 0.1 \%$ aprotinin, $\mathrm{pH}=7.4$ ) at a ratio of $1: 2$ $(\mathrm{w} / \mathrm{v})$. After centrifugation of the homogenates $\left(12,000 \mathrm{rpm}, 30 \mathrm{~min}, 4^{\circ} \mathrm{C}\right)$, the supernatant was stored at $-80^{\circ} \mathrm{C}$. Sandwich ELISA kits (Bio-sense, Norway) were used to determine the VTG concentration (Holbech et al. 2001). Briefly, a 96 well microplate was coated at $37^{\circ} \mathrm{C}$ for $2 \mathrm{hr}$ with polyclonal antibody against $\mathrm{zf}$ VTG [100 $\mu \mathrm{l} /$ well, dilution with carbonate buffer (CBS, $0.05 \mathrm{M}, \mathrm{pH}=9.6$ )]. After washing three times with PBST buffer [0.05\% Tween 20 in PBS $(0.01 \mathrm{M}, \mathrm{pH}=$ 7.6)], the plate was blocked with BSA ( $1 \%$ ) for $2 \mathrm{hr}$ at $37^{\circ} \mathrm{C}$. After washing with PBST buffer three times, the samples were added into wells, and incubated at 37 ${ }^{\circ} \mathrm{C}$ for $1 \mathrm{hr}$. Then, the plate was incubated at $37^{\circ} \mathrm{C}$ for $1 \mathrm{hr}$ with monoclonal antibody and subsequently with goat anti-mouse IgG-horseradish peroxidase (Zhongshan, Beijing). The plate was washed, and then $100 \mu \mathrm{l} /$ well freshly prepared substrate [ $3 \mathrm{mg} / \mathrm{ml}$ of $p$-nitrophenyl phosphate (Sigma, 104-105, USA) in substrate buffer ( $100 \mathrm{mM}$ sodium phosphate, $50 \mathrm{mM}$ sodium citrate, $0.05 \% \mathrm{H}_{2} \mathrm{O}_{2}$; $\mathrm{pH}=5.0$ )] was added. The color reaction was stopped after about $30 \mathrm{~min}$ in the dark by adding $50 \mu \mathrm{I} \mathrm{H}_{2} \mathrm{SO}_{4}(2 \mathrm{M})$. Absorbance (OD) was read at $490 \mathrm{~nm}$ with a microplate reader (Bio-rad 550). The working range of the VTG standard curve was from 0.25 to $31.3 \mathrm{ng} / \mathrm{ml}$.

In order to determine possible impacts of EDCs in effluents during early-life development, the larval medaka (Oryzias latipes) 30-day post hatch was exposed to the effluents before and after chlorination. In brief, 40 larvae were exposed to effluents before and after chlorination in a 40 -liter chamber, carried out with a similar laboratory-constructed flow-through system as described above. Each chamber was divided into two with a mesh partition. The larvae from each group were divided into two subgroups and placed into two chambers, that is, 10 larvae and the other 30 larvae were apart in the same exposure chamber. One subgroup (10 larvae) was monitored after exposure 1, 2, 3 and 4 weeks. This was being 
monitored continuously by measuring the lengths and weights. All of the larvae were fed twice with hatched shrimp freshly (INVE, USA).

500 - ml effluent samples were collected daily, and stored at $4{ }^{\circ} \mathrm{C}$. After two weeks, all samples were mixed thoroughly and two liters were used for analyzing PAHs. After the samples were first filtered with $0.45 \mu \mathrm{m}$ glass fiber filter paper (Whatman) and the $\mathrm{pH}$ was adjusted to 2 - 3, each sample was percolated through a C18 solid phase extraction cartridge (Waters, USA), and then $5 \mathrm{ml}$ hexane and 5 $\mathrm{ml}$ dichloromethane were used to elute the cartridge. The eluate was dried under a gentle stream of nitrogen, and then dissolved in $100 \mu \mathrm{l}$ of hexane. The mass spectrometer (Q-Mass-910, HP) was operated in the electron impact ionization mode with an ionizing energy of $70 \mathrm{eV}$. The injector temperature was maintained at $280^{\circ} \mathrm{C}$, and the transmission line temperature was kept at $260^{\circ} \mathrm{C}$. An HP - 5MS capillary column was programmed to increase from $40^{\circ} \mathrm{C}$ to $280^{\circ} \mathrm{C}$ at $10^{\circ} \mathrm{C} / \mathrm{min}$ (keeping this temperature for $10 \mathrm{~min}$ ). Injection was performed in the splitless mode and helium was used as the carrier gas. 2 - $\mu$ l samples were injected manually. The detection limits and recoveries of PAHs were listed in Table 1.

Table 1. Recoveries and detections limit of PAHs

\begin{tabular}{|l|c|c|}
\hline \multicolumn{1}{|c|}{ PAHs } & Detection limit $(\mathrm{ng} / \mathrm{L})$ & Recovery $(\%)$ \\
\hline naphthalene & 0.33 & 69.2 \\
\hline acenaphthene & 0.17 & 117.7 \\
\hline phenanthrene & 0.42 & 119.8 \\
\hline anthracene & 0.33 & 62.8 \\
\hline fluoranthene & 0.25 & 104.4 \\
\hline pyrene & 0.13 & 120.9 \\
\hline benzo(a)anthracene & 0.13 & 81.3 \\
\hline chrysene & 0.13 & 92.3 \\
\hline benzo(a)pyrene & 2.00 & 76.8 \\
\hline indeno(1,2,3-cd)pyrene & 1.25 & 113.5 \\
\hline dibenzo(a,h)anthracene & 3.33 & 95.2 \\
\hline
\end{tabular}

One-way analysis of variance (ANOVA) was used to determine differences in VTG induction and growth among experimental groups. Differences were considered significant if $p<0.05$.

\section{RESULTS AND DISCUSSION}

As shown in Figure 1, VTG concentrations in secondary effluents were 1362.1 \pm $221.7 \mathrm{ng} / \mathrm{ml}$, which was significantly lower than that in the control $(2236.1 \pm$ 


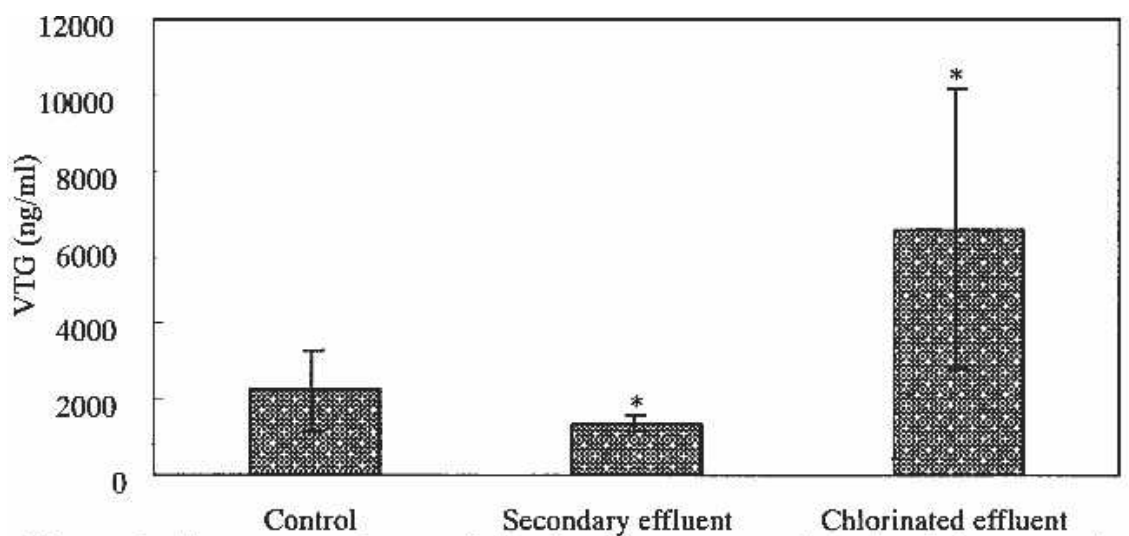

Figure 1. Vtg suppression or induction in mature male zebrafish exposed to secondary effluent or chlorinated effluent. Asterisk indicates that the Vtg concentrations in zebrafish exposed to effluents changed significantly compared with that in the control $(p<0.05) . *, p<0.05$.

$1067.6 \mathrm{ng} / \mathrm{ml})(p<0.05)$. This phenomenon was similar to the results reported by COMPREHEND (Pickering and Sumpter. 2003); that is, some effluents did not induce VTG in vivo even if significant estrogenic activities were detected in vitro. To better understand this issue, some PAHs suggested by the US EPA as principal contaminants of effluents were analyzed. Antiestrogenicities for these agents were reported by Arcaro et al. (1999). As a result, five PAHs, acenaphthene, phenanthrene, anthracene, fluoranthene, and dibenzo(a,h)anthracene, were detected and the total concentration was $887 \mathrm{ng} / \mathrm{L}$ in secondary effluents (Table 2). Such a concentration level would induce limited antiestrogenicity according to the results reported by Engwall et al. (1997). At the same time, we found that the larvae lengths and weights in secondary effluents were obviously lower than that in the control group after two weeks exposure $(p<0.05$, Figures 2 and 3 ), suggesting that the secondary effluent had a negative effect on normal physiological metabolism, which would result in a lack of significant VTG induction, in contrast to the control.

On the other hand, the VTG concentration in chlorinated effluents was $6481.8 \pm$ $3682.5 \mathrm{ng} / \mathrm{ml}$, which is about three times and four times higher than those in the control and in the secondary effluent $(p<0.05)$, respectively (Figure 1$)$. That is, from the view of VTG induction, the estrogenicity of chlorinated effluent became obvious. In fact, some studies have found that several endocrine disrupting chemicals (EDCs) such as 178 - estradiol (E2) and bisphenol A (BPA) can be reactive with $\mathrm{NaOCl}$ during the chlorination process, and their by - products still showed estrogenic activity after chlorination based on both in vivo and in vitro studies (Hu et al. 2002; Tabata et al. 2003; Alum et al. 2004). Therefore, the 


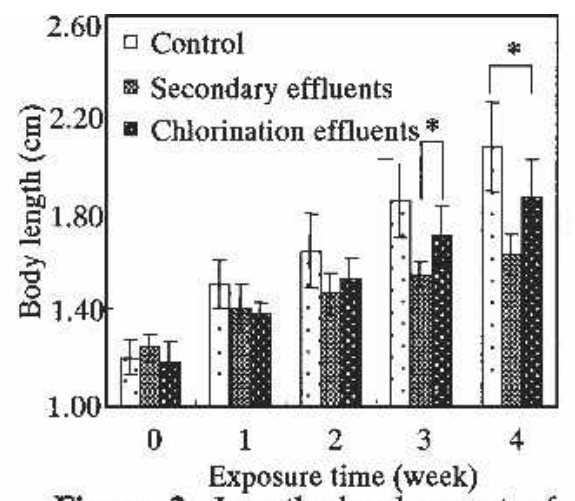

Figure 2. Length development of larval medaka exposed to the secondary effluents before and after chlorination for four weeks ( $\mathrm{n}=$ 10). $*, p<0.05$

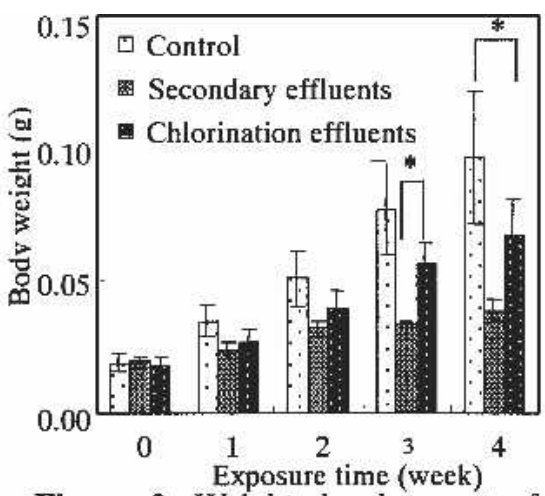

Figure 3. Weight development of larval medaka exposed to the secondary effluents before and after chlorination for four weeks ( $\mathrm{n}=$ 10). $*, p<0.05$

increase of VTG induction in effluents after chlorination cannot be attributed only to the changes of estrogenic activity. In fact, the estrogenic activity of the chlorinated secondary effluent based on the in vitro test has been demonstrated to be lower than that of the effluent before chlorination (Wang 2004). As shown in Figures 2 and 3, the larval growth in chlorinated effluents was faster than that in secondary effluents after 3-week exposure $(p<0.05)$, although it was significantly lower than that in the control after 4 -week exposure $(p<0.05)$. These results suggested that the water quality of the effluents after chlorination was improved, which was also demonstrated from the approximately $54.2 \%$ removal of PAHs (Table 2). Thus, VTG in chlorinated effluents was induced by the remaining estrogenic activity when the negative effects on the normal physiological metabolism became weak.

Table 2. PAH concentrations ( $\mathrm{ng} / \mathrm{L}$ ) in secondary effluent before and after chlorination

\begin{tabular}{|c|c|c|c|}
\hline & Control & $\begin{array}{c}\text { Secondary } \\
\text { effluents }\end{array}$ & $\begin{array}{c}\text { Chlorinated } \\
\text { effluents }\end{array}$ \\
\hline Acenaphthene & ND & 132 & 67 \\
\hline Phenanthrene & ND & 291 & 156 \\
\hline Anthracene & ND & 397 & 183 \\
\hline Fluoranthene & ND & 61 & ND \\
\hline Dibenz(a,h)anthracene & ND & 6 & ND \\
\hline Total & & 887 & 406 \\
\hline
\end{tabular}

ND: no detection 
In this paper, we reported that the phenomenon of VTG in fish was not induced by exposure to secondary effluents, while the induction of VTG of fish exposed to chlorinated effluents was improved. The mechanism underlying our observations needs to be further investigated.

Acknowledgments. We thank the Center of Water Quality Testing of Gaobeidian Sewage Treatment Plant for technical assistance. This work was funded by the National Natural Science Foundation of China [40021101].

\section{REFERENCES}

Alum A, Yoon Y, Westerhoff P, Abbaszadegan M (2004) Oxidation of bisphenol A, 17 beta-estradiol, and 17 alpha-ethynyl estradiol and by-product estrogenicity. Environ Toxicol 19: 257-264

Arcaro KF, O'Keefe PW, Yang Y, Clayton W, Gierthy JF (1999) Antiestrogenicity of environmental polycyclic aromatic hydrocarbons in human breast cancer cells. Toxicology 133: 115-127

Engwall M, Broman D, Dencker L, Naf C, Zebuhr Y, Brunstrom B (1997) Toxic potencies of extracts of sediment and settling particulate matter collected in the recipient of a bleached pulp mill effluent before and after abandoning chlorine bleaching. Environ Toxicol Chem 16: 1187-1194

Holbech H, Andersen L, Petersen GI, Korsgaard B, Pedersen KL, Bjerregaard P (2001) Development of an ELISA for vitellogenin in whole body homogenate of zebrafish (Danio rerio). Comp Biochem Phys C 130: 119-131

Hu JY, Xie GH, Aizawa T (2002) Products of aqueous chlorination of 4-nonylphenol and their estrogenic activity. Environ Toxicol Chem 21: 2034-2039

Jobling S, Nolan M, Tyler CR, Brighty G, Sumpter JP (1998) Widespread sexual disruption in wild fish. Environ Sci Technol 32: 2498-2506

Pickering AD, Sumpter JP (2003) Comprehending endocrine disrupters in aquatic environments. Environ Sci Technol 37: 324A-336A

Rodgers-Gray TP, Jobling S, Morris S, Kelly C, Kirby S, Janbakhsh A, Harries JE, Waldock MJ, Sumpter JP, Tyler CR (2000) Long-term temporal changes in the estrogenic composition of treated sewage effluent and its biological effects on fish. Environ Sci Technol 34: 1521-1528

Rodgers-Gray TP, Jobling S, Kelly C, Morris S, Brighty G, Waldock MJ, Sumpter JP, Tyler CR (2001) Exposure of juvenile roach (Rutilus rutilus) to treated sewage effluent induces dose-dependent and persistent disruption in gonadal duct development. Environ Sci Technol 35: 462-470

Tabata A, Miyamoto N, Ohnishi Y, Itoh M, Yamada T, Kamei T, Magara Y (2003) The effect of chlorination of estrogenic chemicals on the level of serum 
vitellogenin of Japanese medaka (Oryzias latipes). Water Sci Technol 47:51-57

Wang W (2004) Bioassay for screening AhR compounds and monitoring AhR in the municipal sewage treatment plant. M.S.thesis, Peking University, China 